Case Reports in
Gastroenterology
Case Rep Gastroenterol 2020;14:497-503

DOI: 10.1159/000509503

Published online: October 20, 2020 (c) 2020 The Author(s)

Published by S. Karger AG, Basel www.karger.com/crg

This article is licensed under the Creative Commons Attribution-NonCommercial 4.0 International License (CC BY-NC) (http://www.karger.com/Services/OpenAccessLicense). Usage and distribution for commercial purposes requires written permission.

\title{
An Extremely Rare Presentation of an Alpha-Fetoprotein-Producing Esophageal Adenocarcinoma
}

\author{
Yaser Khalid ${ }^{a}$ Neethi Dasu ${ }^{b}$ Debashis Rejac ${ }^{c}$ Herman Suga $^{d}$ \\ Michael Itidiare $^{b} \quad$ Kirti Dasu $^{\mathrm{e}}$ Richard Walters $^{\mathrm{b}} \quad$ Richard Gordon $^{f}$ \\ aDivision of Internal Medicine, Memorial Healthcare System, Hollywood, FL, USA; \\ ${ }^{b}$ Division of Gastroenterology, Rowan University School of Medicine at Jefferson Health \\ System, Stratford, NJ, USA; 'Division of Internal Medicine, Rutgers Robert Wood Johnson \\ Medical School, New Brunswick, NJ, USA; dDivision of Internal Medicine, Rowan University \\ School of Medicine at Jefferson Health System, Stratford, NJ, USA; eDivision of Biology, \\ Syracuse University, Syracuse, NY, USA; fDivision of Hematology/Oncology, \\ Comprehensive Cancer and Hematology Specialists, Voorhees, NJ, USA
}

\section{Keywords}

Esophageal cancer · Gastroesophageal reflux disease · Hepatocellular cancer .

Alpha-fetoprotein

\begin{abstract}
Alpha-fetoprotein (AFP)-producing esophageal adenocarcinoma (EAC) is an extremely rare occurrence with very few cases reported in the literature. We report the case of a 76 -year-old female who presented with progressive weakness, fatigue, and a decrease in appetite for weeks and who was found to have an AFP-producing EAC with an extraordinarily high AFP level of $46,135 \mathrm{ng} / \mathrm{mL}$. CT angiography revealed abnormal thickening of the esophagus and multiple metastatic masses throughout the liver. Upper endoscopy revealed a large mass in the distal esophagus with extension into the stomach. Biopsy confirmed the EAC. Most cases are unsuccessfully treated with surgery and chemotherapy. Serial measurement of serum AFP may be useful for monitoring clinical status and treatment response.




\section{Case Reports in Gastroenterology}

Case Rep Gastroenterol 2020;14:497-503

DOI: $10.1159 / 000509503$

(c) 2020 The Author(s). Published by S. Karger AG, Basel www.karger.com/crg

Khalid et al.: An Alpha-Fetoprotein-Producing Esophageal Adenocarcinoma

\section{Introduction}

Alpha-fetoprotein (AFP)-producing esophageal adenocarcinoma (EAC) is an extremely rare occurrence and very few cases have been reported in the literature. AFP is a glycoprotein that is normally produced by the fetal liver and yolk sac and production begins at the sixth week of gestation. AFP levels normalize to $10-15 \mathrm{ng} / \mathrm{mL}$ (normal $<12 \mathrm{ng} / \mathrm{mL}$ ) within the first year of infancy [1]. Elevated AFP level is a tumor marker that signals malignant transformations; however, elevated AFP levels are rarely associated with EACs. AFP-producing EACs can be classified into two histological subtypes: hepatoid adenocarcinoma (HAC) or an AFPproducing EAC. EAC tumors have a poor prognosis due to late stage presentation and/or insidious symptoms. A barium study, biopsy, or endoscopy is necessary to confirm the diagnosis, and then further investigation via immunohistochemical investigation is needed in order to avoid miscategorization as well as for subtype differentiation [2-4]. Immunohistochemistry stains can further establish whether the tumor originated in the esophagogastric junction or metastasized from the liver. In the presence of an AFP-producing liver lesion with hepatoid features, metastatic disease from hepatocellular carcinoma (HCC) is often positive for cytokeratin 19 or alpha- 1 antitrypsin [5]. In cases of late-presentation, surgery for an EAC is considered futile, especially for patients who present with multiple comorbidities [6]. AFP-producing tumors and EACs are known for their chemoresistance, further complicating treatment options [2]. Serial measurement of serum AFP has been shown to be useful for monitoring clinical status and treatment response. Clinicians should consider AFP-producing EAC in their differential diagnosis when working up a liver mass in the setting of liver dysfunction or an elevated AFP level, especially in the absence of chronic liver disease [1].

\section{Case Report}

A 75-year-old female with a past medical history of gastroesophageal reflux disease and Barrett's esophagus status post multiple upper endoscopies and colonoscopies presented with progressive weakness, fatigue, diminished appetite, and diffuse abdominal pain for 3 weeks. The patient stated that she was actively undergoing acupuncture treatments, which relieved her symptoms of gastroesophageal reflux disease over the last 3-5 years until her symptoms returned 1 month prior to admission. She denied any family history of gastrointestinal malignancy. She admitted having occasional dysphagia for solid food, recent weight loss of approximately $5 \mathrm{lbs}$ during the past month, progressive generalized weakness, and a fall. On admission, her vitals were unremarkable except for tachycardia with a heart rate of 123 beats/min. On physical examination, she was alert and responsive. Her abdomen was soft with no guarding, but she had mild epigastric tenderness. Given her tachycardia, a CT angiography of her lungs was done to rule out pulmonary embolism. On this CT angiography, gastric thickening, celiac adenopathy, and multiple large liver masses were incidentally found. This was followed by a CT of her abdomen and pelvis with and without intravenous or oral contrast (Fig. 1).

The patient's labs revealed markedly elevated CEA of $742 \mathrm{ng} / \mathrm{mL}$ (normal $\leq 3 \mathrm{ng} / \mathrm{mL}$ ), an AFP of $46,135 \mathrm{ng} / \mathrm{mL}$ (normal $<12 \mathrm{ng} / \mathrm{mL}$ ), and a CA19-9 of 6,842 U/mL (normal 0-37 U/mL). Then an upper endoscopy revealed a large mass in the distal esophagus that was not fully obstructing the lumen, but the mass did extend into the stomach (Fig. 2).

Biopsies of the mass and immunohistochemistry stains were performed to confirm EAC. The patient's tumor markers did not confirm any findings of Barrett's epithelium or any 


\section{Case Reports in Gastroenterology}

Case Rep Gastroenterol 2020;14:497-503

DOI: $10.1159 / 000509503$

(c) 2020 The Author(s). Published by S. Karger AG, Basel www.karger.com/crg

Khalid et al.: An Alpha-Fetoprotein-Producing Esophageal Adenocarcinoma

mucosal changes to reflect reflux esophagitis. The tissue was negative for HER-2, which can be seen in up to $20 \%$ of gastroesophageal adenocarcinomas, and immunohistochemical stains were positive for CDX2, CK7, and Heppar1 and negative for CK20, further confirming that the tumor was less likely due to metastasis from HCC in the liver based on the histochemical properties (Fig. 3). Needle aspiration biopsy of one of the large lesions in her liver with staining for AFP revealed EAC with metastasis to the liver (Fig. 4, 5). A Port-A-Cath was placed by General Surgery and the patient was discharged from the hospital and scheduled for outpatient follow-up.

In the outpatient office, she was treated with palliative chemotherapy-FOLFOX regimen. She experienced weakness, fatigue, nausea, decrease in appetite, and weight loss and stated that these symptoms occurred around 3-4 days after starting treatment. A repeat CT scan showed significant decrease in size of the known liver metastasis.

The patient presented again to the hospital after several months for a blood transfusion for symptomatic anemia of neoplastic disease. The patient stated that she began to have a slowly worsening progression of exertional dyspnea over the 3 months since the prior hospitalization. A CT of the chest and abdomen was obtained to evaluate her symptoms of dyspnea and showed progression of metastatic disease in the liver with an increase in the size of the largest focus although her metastatic lymphadenopathy remained unchanged.

\section{Discussion}

AFP-producing EACs are extremely rare neoplasms that generally have a poor prognosis as these tumors are identified in advanced stages and are often insidious in nature. They are classified by two distinguished histological subtypes: HAC or AFP-producing EACs. HAC is defined as an adenocarcinoma that exhibits histological characteristics resembling hepatic cells or HCC. In contrast, AFP-producing EACs exhibit no hepatic characteristics on histological examination [1]. The general workup for an EAC is extensive as these tumors generally require multiple biopsies of the esophagus and liver to confirm the etiology of the esophageal mass; the distinguishing factors are the pathological results of histochemical and immunohistochemical stains. In our particular case, histopathological stains were negative for HER-2. Immunohistochemical stains were positive for CDX2, CK7, and Heppar1 and negative for CK20, which ruled out HAC and confirmed the diagnosis of EAC (Fig. 3).

Although increased AFP levels are most commonly associated with HCC, increased AFP levels have been detected in several malignant tumors of various organs, such as the stomach, lung, pancreas, colon, bladder, and ovary. Esophageal cancer and small intestinal neoplasm have the lowest percentage of elevated AFP. Our patient presented not only with EAC but also with extremely high levels of AFP ( $>40,000 \mathrm{ng} / \mathrm{mL}$ ), which has previously been reported only once to our knowledge by Chiba et al. [7] with an AFP of 326,400 ng/mL making this a tremendously rare presentation. Wahren et al. [8] reported serum AFP levels of $5 \mathrm{ng} / \mathrm{mL}$ in $18 \%$ of 55 cases of EAC, with $320 \mathrm{ng} / \mathrm{mL}$ being the highest reported AFP level. Previous studies have reported that EACs are generally located over the lower third of the esophagus and have been associated with a prior history of Barrett's esophagus, as seen in our patient [9-11]. Additional risk factors for EAC include smoking, obesity, and certain epidermal growth factor polymorphisms.

Furthermore, the serum AFP level can be serially measured for monitoring clinical status, evaluating effectiveness of treatment, and assessing recurrence or metastases. The serum AFP level in some patients decreases to within normal limits following surgery, but there is no 


\section{Case Reports in Gastroenterology}

\begin{tabular}{l|l}
\hline Case Rep Gastroenterol 2020;14:497-503 \\
\hline DOI: 10.1159/000509503 & $\begin{array}{l}\text { @ 2020 The Author(s). Published by S. Karger AG, Basel } \\
\text { www.karger.com/crg }\end{array}$ \\
\hline
\end{tabular}

Khalid et al.: An Alpha-Fetoprotein-Producing Esophageal Adenocarcinoma

change following radiation [6]. This indicates that surgery and chemotherapy are useful therapeutic methods for patients with esophageal carcinoma. While elevations in CEA, CA19-9, and b-HCG can be seen in esophageal carcinoma, few reports have described elevations of AFP in the setting of EAC.

Finally, most cases previously stated in the literature were treated with adjuvant chemotherapy and cisplatin plus 5-fluorouracil as first-line therapy; the combination of paclitaxel and cisplatin was used as second-line treatment [7, 12-16]. The results of these treatment regimens were mostly disappointing. Currently, there is no consensus on the best strategy for treating AFP-producing esophageal cancers, thus highlighting the importance and necessity of further clinical trials to explore treatment options. Our patient was treated with FOLFOX, which is oxaliplatin, folinic acid, and 5-fluorouracil. She had temporary reduction of metastasis, but unfortunately there was recurrence.

\section{Statement of Ethics}

Informed consent for publication was obtained from the patient's family member/power of attorney. All research was completed per Declaration of Helsinki guidelines.

\section{Conflict of Interest Statement}

The authors have no conflicts of interest to declare.

\section{Funding Sources}

None.

\section{Author Contributions}

All authors approved the final version of the manuscript. Y. Khalid and N. Dasu: conception of the work, data analysis and interpretation, critical revision of the article, and final approval of the version to be published. R. Walters: conception of the work, data analysis and interpretation, and critical revision of the article. M. Itidiare: data collection, data analysis and interpretation, and critical revision of the article. H. Suga, D. Reja, R. Gordon, K. Dasu: data collection, data analysis and interpretation, and drafting of the article.

\section{References}

1 Wang J, Liu W, Parikh K, Post AB. Alpha-fetoprotein-producing esophageal adenocarcinoma: a mimicker of hepatocellular carcinoma. Clin J Gastroenterol. 2017 Feb;10(1):7-12.

2 Sun N, Yin X, Zhong Y, Zhang X, Xie Y, Meng X, et al. Misdiagnosis of an $\alpha$-fetoprotein-producing esophageal carcinoma: A case report and literature review. Oncol Lett. 2016 Jul;12(1):597-600.

3 Kwon MJ, Byeon S, Kang SY, Kim KM. Gastric adenocarcinoma with enteroblastic differentiation should be differentiated from hepatoid adenocarcinoma: A study with emphasis on clear cells and clinicopathologic spectrum. Pathol Res Pract. 2019 Sep;215(9):152525. 


\section{Case Reports in Gastroenterology}

\begin{tabular}{l|l}
\hline Case Rep Gastroenterol 2020;14:497-503 \\
\hline DOI: 10.1159/000509503 & $\begin{array}{l}\text { @ 2020 The Author(s). Published by S. Karger AG, Basel } \\
\text { www.karger.com/crg }\end{array}$ \\
\hline
\end{tabular}

Khalid et al.: An Alpha-Fetoprotein-Producing Esophageal Adenocarcinoma

4 DiMaio MA, Kwok S, Montgomery KD, Lowe AW, Pai RK. Immunohistochemical panel for distinguishing esophageal adenocarcinoma from squamous cell carcinoma: a combination of p63, cytokeratin 5/6, MUC5AC, and anterior gradient homolog 2 allows optimal subtyping. Hum Pathol. 2012 Nov;43(11):1799807.

5 Kashani A, Ellis JC, Kahn M, Jamil LH. Liver metastasis from hepatoid adenocarcinoma of the esophagus mimicking hepatocellular carcinoma. Gastroenterol Rep (Oxf). 2017 Feb;5(1):67-71.

6 D'Amico TA. Outcomes after surgery for esophageal cancer. Gastrointest Cancer Res. 2007 Sep;1(5):188-96.

7 Chiba N, Yoshioka T, Sakayori M, Mikami Y, Miyazaki S, Akiyama S, et al. AFP-producing hepatoid adenocarcinoma in association with Barrett's esophagus with multiple liver metastasis responding to paclitaxel/CDDP: a case report. Anticancer Res. 2005 Jul-Aug;25(4):2965-8.

8 Wahren B, Harmenberg J, Edsmyr F, Jakobsson P, Ingimarsson S. Possible tumour markers in patients with oesophagus cancer. Scand J Gastroenterol. 1979;14(3):361-5.

9 Tanaka K, Fujiya M, Ijiri M, Takahashi K, Ando K, Nomura Y, et al. A Case of Alpha-Fetoprotein-Producing Adenocarcinoma of the Esophagogastric Junction in which Long-Term Survival Was Achieved by Means of Individualized Multidisciplinary Therapy. J Gastrointest Cancer. 2019 Sep;50(3):617-20.

10 Miyazaki T, Sohda M, Sakai M, Kumakura Y, Yoshida T, Kuriyama K, et al. Multimodality Therapy Including Proton Beam Therapy for AFP Producing Esophageal Cancer with Multiple Liver Metastases. Intern Med. 2018 Aug;57(16):2333-9.

11 Chen YY, Hsu WH, Hu HM, Wu DC, Lin WY. A case of alpha-fetoprotein-producing esophageal adenocarcinoma. Kaohsiung J Med Sci. 2013 Feb;29(2):106-10.

12 Häussler U, Bitzer M, Bösmüller H, Clasen S, Götz M, Malek NP, et al. AFP-producing adenocarcinoma of the esophagogastric junction: report of a case with atypical immunohistochemical findings responding to palliative chemotherapy with 5-fluorouracil, leucovorin, oxaliplatin, and docetaxel (FLOT regime). Z Gastroenterol. 2016 Oct;54(10):1147-50.

13 Kripp M, Ströbel P, Dinter D, Lukan N, Hochhaus A, Hofheinz RD. Alpha-fetoprotein expressing metastatic adenocarcinoma of the esophago-gastric junction responding favorably to capecitabine and oxaliplatin. Anticancer Drugs. 2009 Jan;20(1):75-8.

14 Thrumurthy SG, Chaudry MA, Thrumurthy SS, Mughal M. Oesophageal cancer: risks, prevention, and diagnosis. BMJ. 2019 Jul;366:14373.

15 Kawai H, Sekine S, Sanada T, Andoh T, Takechi Y, Okada S. Alpha-fetoprotein-producing esophageal carcinoma: a case report. Anticancer Res. 2003 Sep-Oct;23(5A):3837-40.

16 Kobayashi N, Ohbu M, Kuroyama S, Kikuchi S, Shimao H, Mitomi H, et al. Alpha-fetoprotein-producing esophageal adenocarcinoma: report of a case. Surg Today. 2001;31(10):915-9.
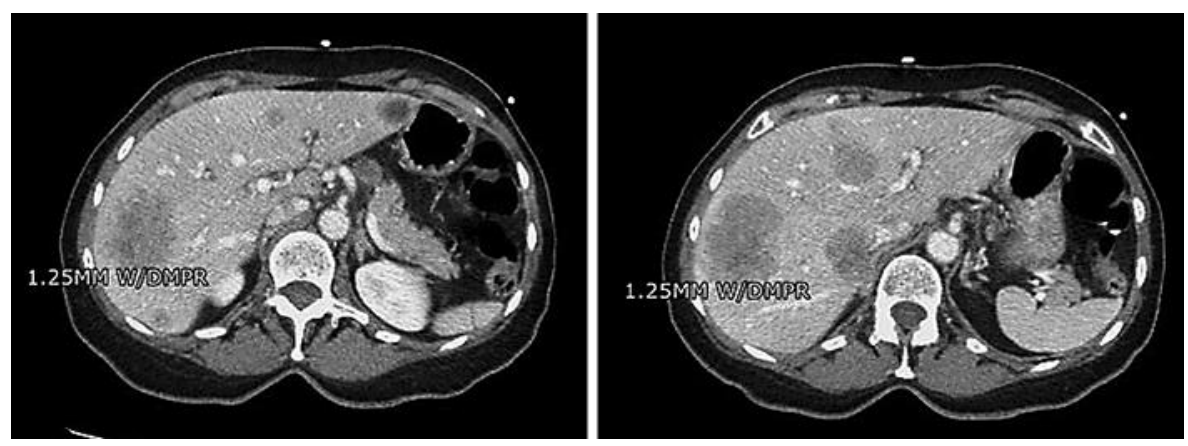

Fig. 1. CT of the abdomen and pelvis with and without intravenous or oral contrast revealing metastatic lesions of the liver. 
Case Reports in Gastroenterology
Case Rep Gastroenterol 2020;14:497-503

DOI: $10.1159 / 000509503$

(c) 2020 The Author(s). Published by S. Karger AG, Basel www.karger.com/crg

Khalid et al.: An Alpha-Fetoprotein-Producing Esophageal Adenocarcinoma
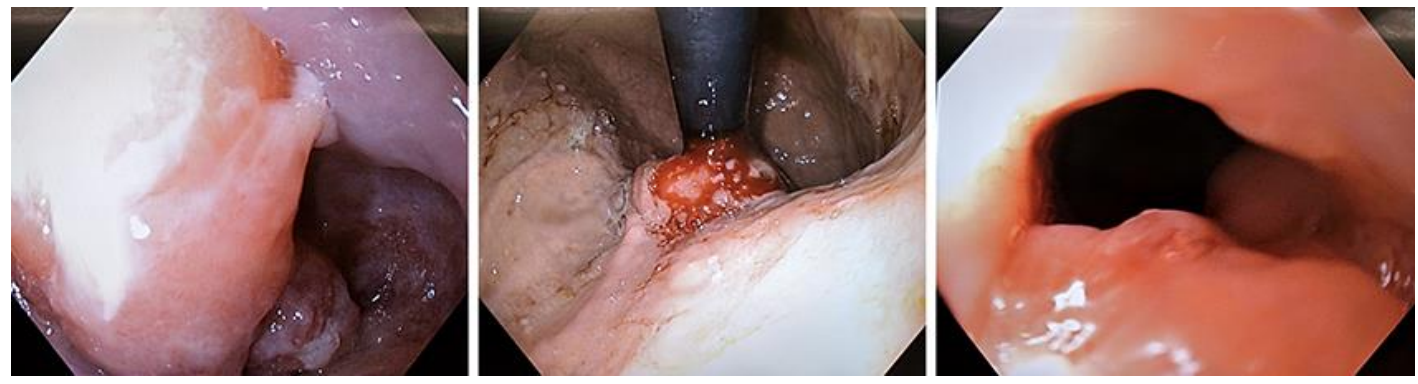

Fig. 2. Endoscopy with large mass noted in the distal esophagus, same mass in the distal esophagus with bleeding noted, and same mass from the distal esophagus extending into the stomach.
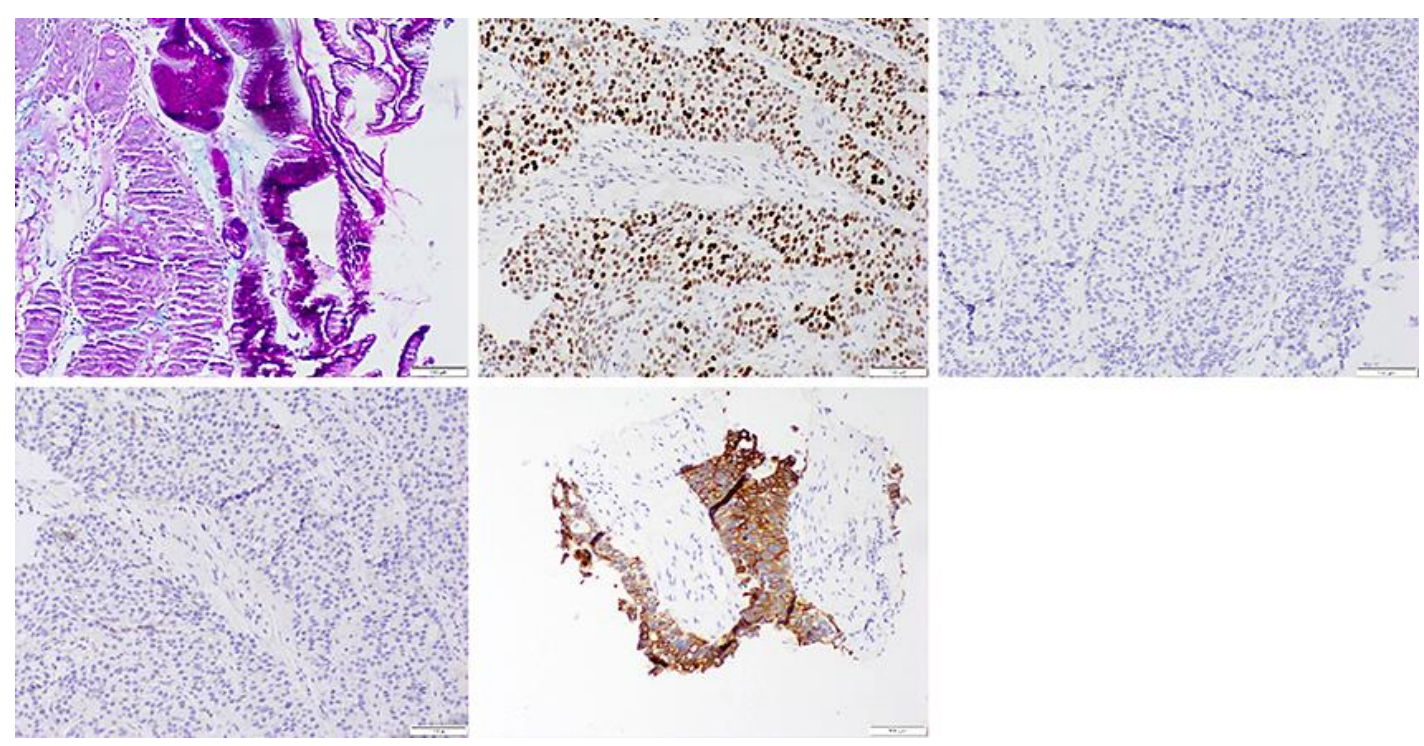

Fig. 3. 100 $\times$ magnification of the esophageal mass: Alcian blue stain, CDX2 stain, chromogranin stain, synaptophysin stain, and 100× magnification of liver mass: CK7 immunohistochemical stain. 
Case Reports in Gastroenterology
Case Rep Gastroenterol 2020;14:497-503

DOI: $10.1159 / 000509503$ (c) 2020 The www.karger.com/crg

Khalid et al.: An Alpha-Fetoprotein-Producing Esophageal Adenocarcinoma

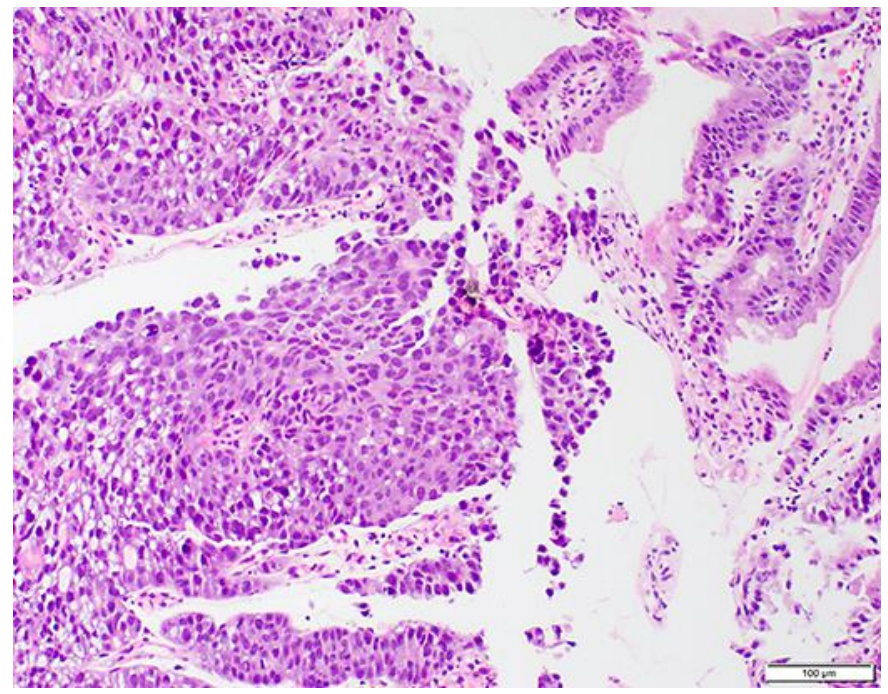

Fig. 4. 100× magnification hematoxylin and eosin stain of adenocarcinoma - esophagus.

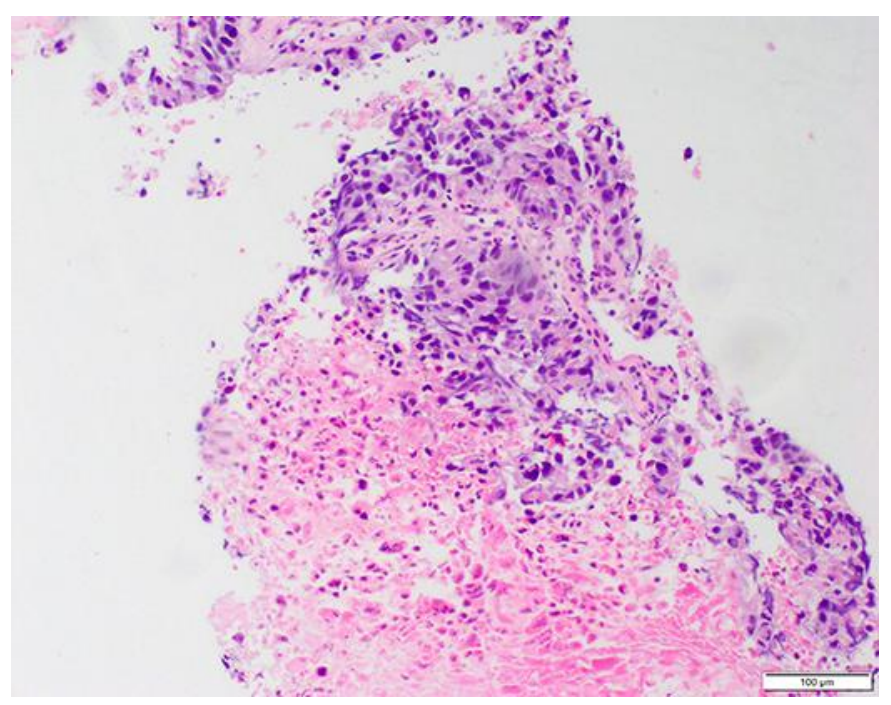

Fig. 5. 100 $\times$ magnification hematoxylin and eosin stain of metastatic adenocarcinoma - liver. 